\title{
Experimental and numerical study of the domestic hot water production with PV panels and a heat pump
}

\author{
F. J. Aguilar ${ }^{1}$, D. Crespi ${ }^{1}$ and P. V. Quiles ${ }^{1, *}$ \\ ${ }^{1}$ University Miguel Hernández of Elche, Mechanical Engineering and Energy Department, Spain
}

\begin{abstract}
This article presents an experimental and modelling work which uses a compact domestic hot water heat pump (DHW-HP) that is simultaneously powered from photovoltaic panels (PV) and from the grid. Results from more than 240 days of experimental works have been used in order to develop and to validate the computer model of the system. The program, implemented in MATLAB, is computationally 'light' enough to allow mid-term simulations yet also detailed enough to accurately and coherently portray stratification within thermal storage tanks. Finally, as an example of the model capabilities, it has been used to simulate a domestic hot water tapping cycle from the European Standard EN 16147.
\end{abstract}

\section{Introduction}

Among the near zero energy building (nZEB) [1] requirements to come, the energy use of air conditioning (HVAC) systems in buildings will be reduced to a value lower than $20 \mathrm{kWh} / \mathrm{m}^{2}$ year. Therefore, energy demand for DHW (that cannot be reduced, since it depends mainly on the number of people) will make up around $50 \%$ of the total thermal demand in dwellings.

The recently approved Directive of Building Energy Efficiency (2018/844/EU) [2] proposes strategies focused on the objective of achieving decarbonized and highefficiency buildings by the year 2050. In addition, the EU has set a binding target to reduce $\mathrm{CO}_{2}$ emissions by at least $80-95 \%$, when compared to 1990 levels, by 2050 . This will favour electrical energy consumption over fossil fuels like Natural Gas or LPG.

In this scenario, heat pumps (HP) used for DHW [3-4] production will play an important role in the coming future. One of the most important parameters within any system that incorporates aerothermal energy is the system's COP. In fact, the EU Commission (2013/114/EU) [5] establishes that unless electrically driven HPs have an SPF greater than 2.5, they cannot be considered a renewable source.

The decrease of the COP at outdoor temperatures below $10^{\circ} \mathrm{C}$ is a noteworthy limitation for heat pumps. Furthermore, defrosting processes [6] also reduce their efficiency significantly.

Many researches in this field are focused on improving the efficiency of heat pumps when they work with low outdoor temperatures. In this sense, Recent reviews [7-8] show that current air heat pumps for domestic hot water production have typical SPF (seasonal COP) between 2.5 and 3.5 when water preparation temperature is below $50^{\circ} \mathrm{C}$. Furthermore, they pointed out that such performance may be improved to 6-9 by adding a solar (thermal and/or photovoltaic) contribution to the system. A well-known technology, commonly called PVT or PVThermal [9-10], is the combination of photovoltaic panels and thermal collectors. In PVT technology, the dissipated heat can be used to heat a secondary fluid, which can be water, air or a refrigerant. In this way, the PV panel can be refrigerated, which increases its efficiency [11] and at the same time the heat can be used in a parallel application. With the combination of a PVT and a heat pump, the heat from the PVT can be used, for example, to increase the operation temperature of the evaporator, as shown in [12-13].

To overcome the difficulties in the existing PVT technologies, [14] and [15] propose to use heat pipes as part of the PVT panels.

A simpler solution than the heat pump with PVT would be the combination of a PV panel and a domestic hot water heat pump. This solution uses the PV energy to power the compressor of the heat pump. The authors carried out in Alicante (South of Spain) an experimental study of a DHW heat pump supported by PV panels during one year [16] and measured an SPF of 6.

Given that any given system's measured COP can be altered so drastically, manufacturers that wish to sell within the EU must test and mark their HPWH in accordance with EN 16147 [17]. The document calculates the COP for heat pump hot water heaters while also accounting for heat loss within water tanks and a series of different 'tapping cycles'. Each tapping cycle is defined as energy extracted ( $\mathrm{kWh}$ hot water equivalent), rather than direct water volume and lasts 24 hours. There are 5 different test cycles (S, M, L, XL and XXL) aimed at reflecting realistic scenarios and allowing for manufacturers to select the test conditions that are most suited to the unit's expected usage.

\footnotetext{
*Corresponding author: pedro.vicente $@$ umh.es
} 
Due to the complexity of the scenarios described within the EN 16147, a precise experimental procedure to test a HPWH results being long and expensive.

The current work is focused in the creation of a heat pump water heater model. The aim is to use the model to simulate the behaviour of the unit under different working conditions, reducing the complexity and cost of the process.

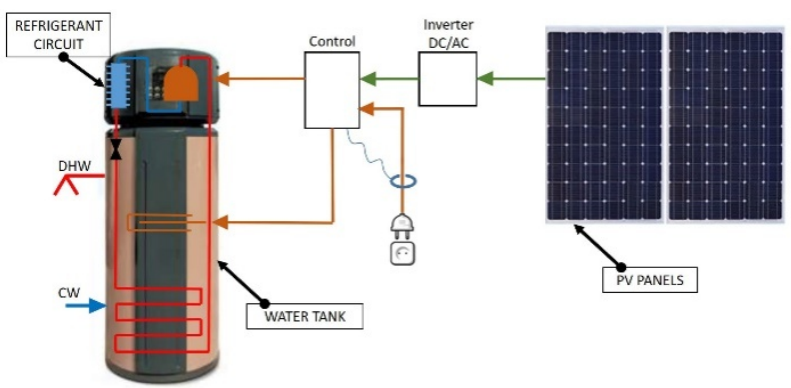

Fig. 1. Solar Heat Pump for DHW

First of all, an experimental work about a DHW heat pump that was powered from photovoltaic panels and from the grid was carried out during an entire year (see Figure 1). Tests were carried out in the University laboratory located in Alicante (Spain) under real climatic conditions, while a recirculation circuit was used to simulate water consumptions.

Finally, the obtained results were used to define and to validate a model of the DHW heat pump previously analyzed, taking into account the water tank and the refrigerant cycle performance.

Once the simulation model was validated, it was used to simulate the curves from Standard EN 16147.

\section{Experimental Facility}

The heat pump analyzed is an ON/OFF equipment with a nominal heating capacity of $1.5 \mathrm{~kW}$ and a nominal electrical consumption of $470 \mathrm{~W}$ (nominal $\mathrm{COP}=3.19$ ). Two photovoltaic panels with a total peak power of 470 $\mathrm{Wp}$ were connected to a micro-converter which was connected to the equipment at $230 \mathrm{Vac}$.

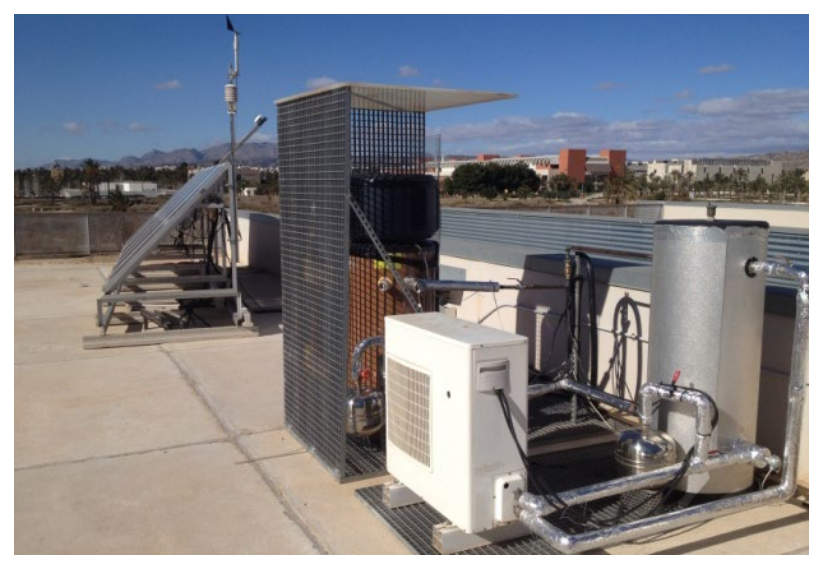

Fig. 2. Photography of the experimental facility
The experimental set-up was installed on the roof of the University's research laboratory located in Elche (Spain). Figure 2 shows a photograph of the facility.

Table 1 shows the technical characteristics of the heat pump for DHW, while Table 2 shows the technical characteristics of the photovoltaic panels.

Table 1. Technical characteristics of the heat pump

\begin{tabular}{|l|c|c|c|}
\hline Kaysun Compak KHP 15 190 & Simb. & Unit & Eco \\
\hline Thermal Capacity & QHP & W & 1500 \\
\hline Compressor Power & PE-COMP & W & 470 \\
\hline COP & COP & $\%$ & 3.19 \\
\hline Electrical Heater Power & QELEC & A & 2000 \\
\hline Refrigerant & --- & --- & R134a \\
\hline Evaporator Fan Power & PE-FAN & W & 30 \\
\hline Tank Volume & V & L & 190 \\
\hline
\end{tabular}

Table 2. Technical characteristics of the PV panels

\begin{tabular}{|l|c|c|c|}
\hline Eurener 235 & Simb. & Unit & Nom. \\
\hline Nominal power & $\mathrm{P}_{\mathrm{N}, \mathrm{PV}}$ & $\mathrm{W}$ & 235 \\
\hline Panel surface area & $\mathrm{APV}_{\mathrm{PV}}$ & $\mathrm{m}^{2}$ & 1.67 \\
\hline Efficiency & $\mathrm{Eff}_{\mathrm{PV}}$ & $\%$ & 13.74 \\
\hline Short circuit current & $\mathrm{I}_{\mathrm{SC}}$ & $\mathrm{A}$ & 8.25 \\
\hline Open circuit voltage & $\mathrm{V}_{\mathrm{OC}}$ & $\mathrm{V}$ & 37.08 \\
\hline Nominal current & $\mathrm{I}_{\mathrm{N}, \mathrm{PV}}$ & $\mathrm{A}$ & 7.66 \\
\hline Nominal voltage & $\mathrm{I}_{\mathrm{N}, \mathrm{PV}}$ & $\mathrm{V}$ & 30.01 \\
\hline NOTC & & ${ }^{\circ} \mathrm{C}$ & 47 \\
\hline$\gamma_{\mathrm{Pmax}}$ & & $\% /{ }^{\circ} \mathrm{C}$ & -0.43 \\
\hline
\end{tabular}

Tests were carried out under real climatic conditions, while a recirculation circuit was used to simulate water consumptions. The facility simulated 6 domestic-hotwater consumptions of 21 liters each one. The heat pump equipment heated the water to $55^{\circ} \mathrm{C}$ and it kept the water temperature higher than $50^{\circ} \mathrm{C}$. The water inlet temperature was between 12 and $15^{\circ} \mathrm{C}$.

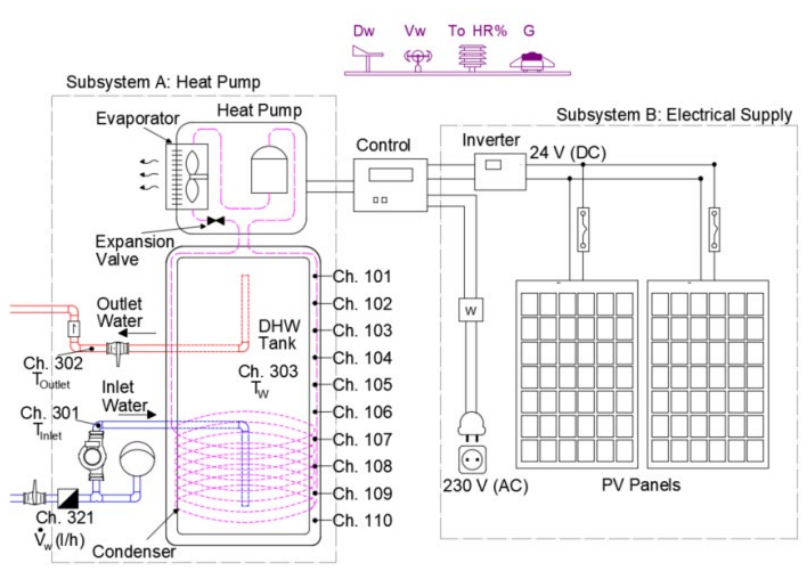

Fig. 3. Experimental facility

During the experimental work more than 240 days were analyzed in detail (at least 20 days per month) in order to 
stablish seasonal results. This experimental work, deeply described in [16], demonstrated that the annual average efficiency of the heat pump ( $\left.\mathrm{SPF}_{\mathrm{HP}}\right)$ was close to 3.5 and the annual average efficiency of the whole system (SPF ${ }_{\text {SYST }}$ ) was near 9, while the solar contribution (SC) was higher than $60 \%$.

On the other hand, several experimental tests were carried out in order to know the behaviour of the water stratification in the tank. This was done via ten thermocouple type $\mathrm{K}$ thermometers positioned along the side of the tank at $10 \mathrm{~cm}$ vertical intervals.

A simplistic long-term experimental tapping cycle was designed to ensure and verify the numerical model's outputs. The tapping cycle was tested for more than three consecutive days to decrease the chances of anomalous results being incorporated into the study.

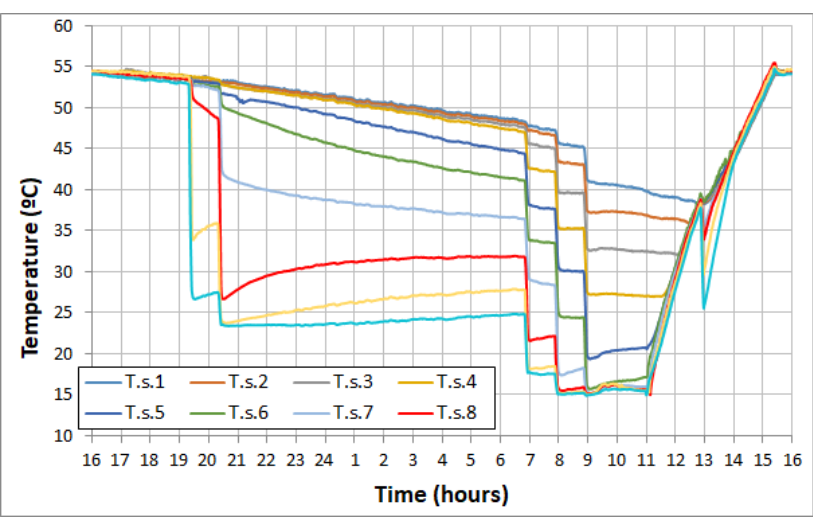

Fig. 4. Experimental results of a DHW consumption type

The tapping cycle consisted of 6 taps of 21 litres every tap at a flow rate of 4 litres/minute at: 19:30, 20:30, 7:00, 8:00, 9:00 and 13:00. The HP was switched ON at 11:30 h. Figure 4 shows the DHW tank temperatures during one of the tests.

\section{System Modelling}

\subsection{Analytical model of the PV Heat Pump}

\subsubsection{Obtaining the model}

In this part of the project, the experimental results were used to develop an analytical model capable of simulating the designed system under different working conditions. The results in steady conditions were joined and collected in order to set an analytical model that illustrated the heat pump performance correctly. For that, non coherent results produced by transitory operation (mainly start-ups, breakdowns and moments of both hot water output and cold water input) have not been discarded. And so, more than 300 valid points were collected.

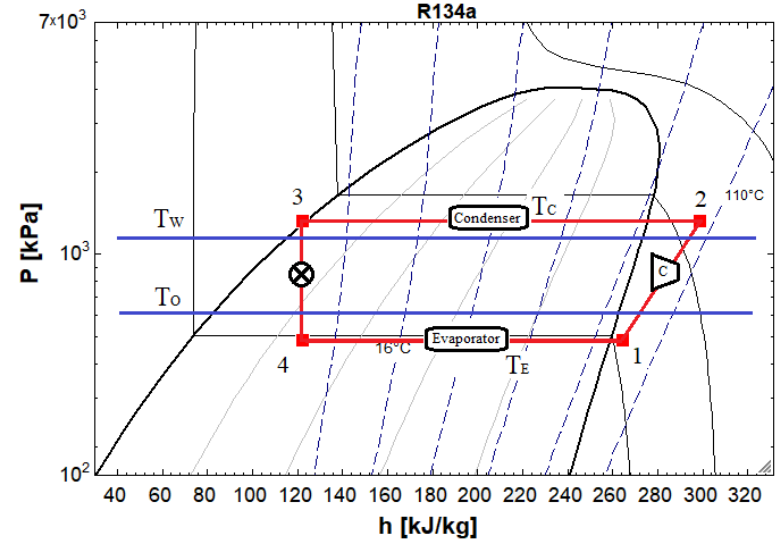

Fig. 5. P-h diagram (R134a)

The dependencies between the different variables were analyzed by using the Excel statistical analysis function. Thus, it was stated that the useful thermal power supplied by the heat pump to the water $\left(\mathrm{Q}_{\mathrm{U}, \mathrm{HP}}\right)$ and the consumed electrical power $\left(\mathrm{P}_{\mathrm{E}, \mathrm{HP}}\right)$ depend mainly on the evaporator temperature $\left(\mathrm{T}_{\mathrm{E}}\right)$ and the condenser temperature $\left(\mathrm{T}_{\mathrm{C}}\right)$ (Figure 5). Also, both the evaporation and the condensation temperatures depend on the outdoor temperature $\left(\mathrm{T}_{\mathrm{O}}\right)$ and the water temperature $\left(\mathrm{T}_{\mathrm{W}}\right)$ at the point where the coil is located (bottom part of the tank).

$$
\begin{gathered}
T_{C}\left({ }^{\circ} \mathrm{C}\right)=7.99+0,18 \cdot T_{O}+0.99 \cdot T_{W} \\
T_{E}\left({ }^{\circ} \mathrm{C}\right)=-14.46+0.65 \cdot T_{O}+0.23 \cdot T_{W} \\
Q_{U, H P}(W)=3434.7+106.5 \cdot T_{E^{-}}
\end{gathered}
$$$$
66.4 \cdot T_{C}+0.77 \cdot T_{E}^{2}+0.41 \cdot T_{C}^{2}-1.03 \cdot T_{E} \cdot T_{C}
$$

$$
P_{E, H P}(W)=310.7-0.10 \cdot T_{E}^{2}+0.51 \cdot T_{C}^{2}+0.10 \cdot T_{E} \cdot T_{C}
$$

The photovoltaic production was calculated as detailed in IDAE [18]. Some factors as cell temperature, temperature loss, inverter performance, etc., are considered in these equations.

$$
\begin{gathered}
T_{C E L L}=T_{O}+(N O C T-20) \cdot G / 800 \\
P_{D C}=P_{P V} \cdot R \cdot\left[1-g T_{C E L L}\right] \cdot G / 1000 \\
P_{A C}=P_{D C} \cdot \eta_{\text {Converter }}
\end{gathered}
$$

Where:
$T_{\text {CELL }}$
NOCT Nominal Operation Cell Temperature $\left({ }^{\circ} \mathrm{C}\right)$
$G \quad$ Solar irradiance $\left(\mathrm{W} / \mathrm{m}^{2}\right)$
$P_{D C} \quad$ Photovoltaic DC power $(W)$
$R \quad$ Losses coefficient
$g \quad$ Temperature coefficient $\left(1 /{ }^{\circ} \mathrm{C}\right)$
$P_{A C} \quad$ Photovoltaic AC power $(W)$
$\eta_{\text {Converter }} \quad$ DC/AC Converter efficiency

By following the procedure described in [16], the thermal energy supplied by the heat pump to the water $\left(\mathrm{E}_{\mathrm{U}, \mathrm{HP}}\right)$, the energy consumed by the heat pump ( $\left.\mathrm{E}_{\mathrm{TOT}, \mathrm{HP}}\right)$ and the energy produced by the PV panels have been obtained. 
The seasonal performance factor and the solar contribution are defined as follows:

- The Seasonal Performance Factor of the heat pump (without taken into account the PV contribution), $\mathrm{SPF}_{\mathrm{HP}}$ is:

$$
S P F_{H P}=\mathrm{E}_{\mathrm{U}, \mathrm{HP}} / \mathrm{E}_{\mathrm{TOT}, \mathrm{HP}}
$$

- The seasonal performance factor of the system $\mathrm{SPF}_{\mathrm{SYS}}$ is defined as the relation between the total heat given to the system $\mathrm{E}_{\mathrm{U}, \mathrm{TOT}}$ and the energy taken from the grid $\mathrm{E}_{\mathrm{GRID}, \mathrm{HP}}$

$$
S P F_{S Y S}=\mathrm{E}_{\mathrm{U}, \mathrm{TOT}} / \mathrm{E}_{\mathrm{GRID}, \mathrm{HP}}
$$

\subsubsection{Validation of the analytical model}

In order to validate the defined model, the described equations of several days of experimental work were applied, taking as input data: the water temperatures at the bottom of the tank $\left(\mathrm{T}_{\mathrm{W}}\right)$, the outdoor temperature $\left(\mathrm{T}_{\mathrm{O}}\right)$ and the solar irradiance $(\mathrm{G})$. The water consumption profile is taken from the experimental results.

In the following figures the obtained results by means the experimental work and the ones obtained by means the model are compared. The high accuracy reached with the power consumed has to be highlighted, where the curves are almost equal.

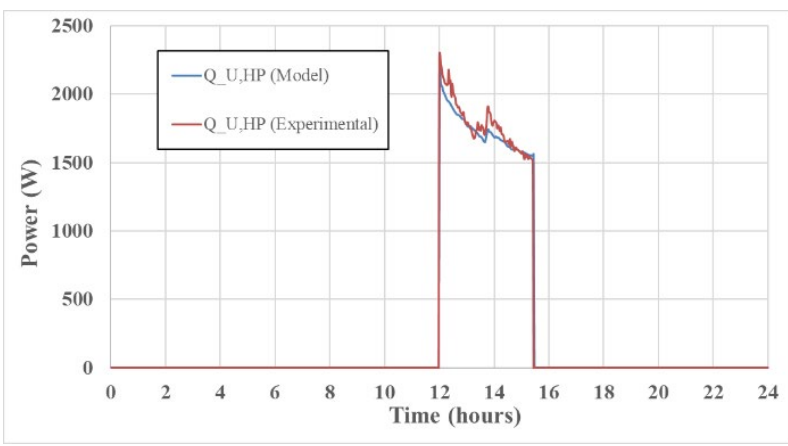

Fig. 6. Useful thermal energy produced by the heat pump. Experimental and analytical result (June 3rd)

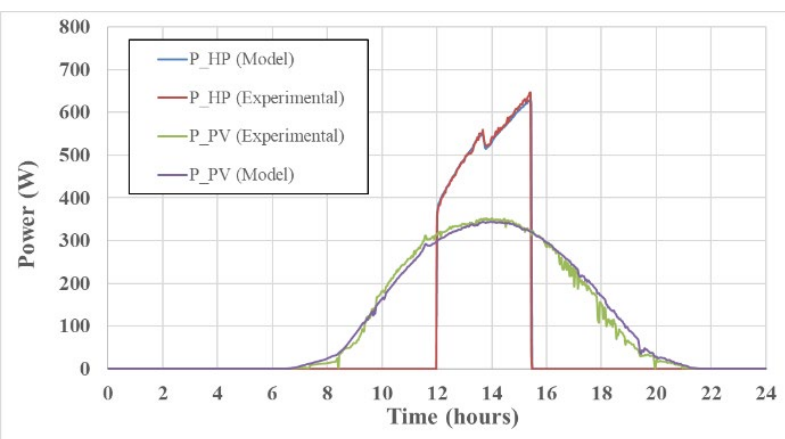

Fig. 7. Energy consumed by the heat pump and energy produced by the PV panels. Experimental and analytical results (June 3rd)

Both figures and Table 3 show that the differences are minimal.

The same procedure has been repeated in more days and all of them have given similar results of errors (Errors below $6 \%$.).
Thus, it can be assumed that the analytical defined model has been correctly validated.

Table 3. Experimental vs. analytical results (June 3rd)

\begin{tabular}{|l|c|c|c|c|}
\hline & Units & Experim. & Model & Error \\
\hline EU.HP $_{\text {EU.HT }}$ & $\mathrm{kWh}$ & 6.11 & 6.01 & $-1.77 \%$ \\
\hline EU.TOT & $\mathrm{kWh}$ & 1.41 & 1.50 & $5.66 \%$ \\
\hline ETOT.HP & $\mathrm{kWh}$ & 1.53 & 7.50 & $-0.37 \%$ \\
\hline EPV.HT & $\mathrm{kWh}$ & 1.41 & 1.82 & $0.68 \%$ \\
\hline EPV.HP & $\mathrm{kWh}$ & 1.17 & 1.15 & $5.66 \%$ \\
\hline EPV.TOT & $\mathrm{kWh}$ & 2.58 & 2.64 & $2.28 \%$ \\
\hline E $_{\text {GRID }}$ & $\mathrm{kWh}$ & 0.65 & 0.67 & $3.82 \%$ \\
\hline SPF & --- & 3.38 & 3.30 & $-2.44 \%$ \\
\hline SPF. & --- & 11.62 & 11.15 & $-4.04 \%$ \\
\hline
\end{tabular}

\subsection{Numerical model of water tank}

\subsubsection{The stratification effect}

As it has been stated in previous section, in order to analyse the performance of the heat pump, it is of the utmost importance to know the water temperature $\left(\mathrm{T}_{\mathrm{W}}\right)$ at the point where the coil is located (bottom part of the tank). In this sense, the stratification effect of the tank may result in considerable water temperature differences between the bottom and the top of the tank.
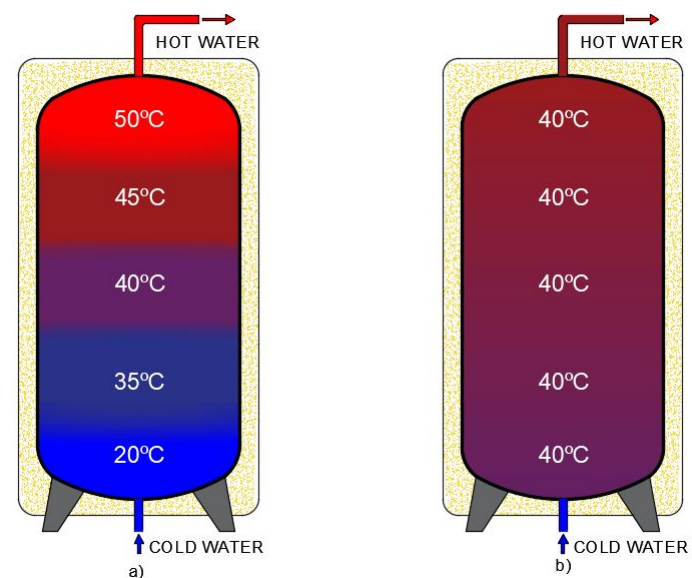

Fig. 8. a) Stratified water tank; b) Mixed water tank

It must be said that stratification is enhanced as a result of DHW draws, where hot water is extracted from the top of the tank, while at the same time cool water enters to the bottom. Thus, in a stratified water tank there are several temperature levels, where the lower levels are cooler than the levels on the top, as Figure 8.a shows.

The stratification phenomenon is particularly important in the case of heat pumps for DHW, since they condense against the lower portion of tanks. Due to stratification, temperatures at the bottom part of the tank are lower, thus achieving greater efficiency.

Conversely, when heat is added via external plate heat exchangers the resulting inlet and outlet jets significantly 
mix the DHW, consequently breaking the fluid stratification. The temperature of the accumulator homogenizes (Figure $8 \mathrm{~b}$ ), which is detrimental to the heat pump's efficiency.

It is important to note that the thermal energy in a stratified tank can be the same than in a mixed tank. In a stratified tank, you may have DHW at $50^{\circ} \mathrm{C}$ at the top of the tank, while in the bottom part, where the HP is heating, the DHW may be at $25^{\circ} \mathrm{C}$, achieving high heat pump efficiencies.

Therefore, a program that simulates stratification within a certain degree of accuracy would greatly benefit both the scientific and the commercial realms. Reliable tank simulations may be a very powerful tool to optimize the systems.

The program, developed in this work with MATLAB, is computationally 'light' enough to allow mid-term simulations yet also detailed enough to accurately and coherently portray stratification within thermal storage tanks.

\subsubsection{Obtaining the model}

As with most mathematical models, the storage tank model was built around a framework of assumptions that echo how well the overall system was understood and how it was expected to behave.

One dimensional heat conduction in the fluid and tank wall was considered: temperature variation was allowed to ensue exclusively in the vertical direction. In all cases, water entering the tank was taken to be colder than the water at the bottom of the tank. Draws were assumed to be instantaneous and provoke complete mixture, due to turbulence and inlet plumes, within a finite and fixed volume of the water within the tank.

The condenser coil was assumed to be at the bottom of the tank and provide constant and instantaneous heat when switched on. Tank loses were considered, but the insulation was assumed to be equally distributed around the surface of the tank.

It was decided that the one-dimensional multinode model would be discretized into finite volumes. As with most multinode storage models, the process began by assuming conservation of energy and formulating an energy rate balance.

Fluid Equation in the tank fluid

$\rho_{F} V_{F} C_{P, F} \frac{\partial}{\partial t}\left(T_{F}\right)=\dot{Q}_{g e n, n}-k_{F} A_{F}\left(\left.\frac{\partial^{2}}{\partial z^{2}}\left(T_{F}\right)\right|_{Z} \cdot \Delta z\right)$

Tank Equation in the wall

$\rho_{W} V_{W} C_{P, W} \frac{\partial}{\partial t}\left(T_{W}\right)=\dot{Q}_{g e n, n}-k_{W} A_{W}\left(\left.\frac{\partial^{2}}{\partial z^{2}}\left(T_{W}\right)\right|_{Z} \cdot \Delta z\right)$

Boundary conditions.

Tank loses

$$
\dot{Q}_{W}=h_{E X T}\left(T_{F}-T_{E X T}\right)
$$

Where $h_{E X T}$ was calculated from specific measurements carried out in the tank in order to estimate it losses.
Thermal flux from the tank to the fluid

$$
\dot{Q}_{F}=h_{F}\left(T_{W}-T_{F}\right)
$$

Where $h_{F}$ was calculated from measurements: it makes a high influence on wall temperature when HP is on.

\section{Heat generation in the tank wall}

When the HP was ON, a high heat was generated in the condenser coil that surrounds the bottom quarter of the tank wall. This heat was supposed to be generated in the tank wall.

\subsubsection{Model adjustment}

\section{Flow mixing in the taps}

Although tank up-flow was not considered to incite significant mixing, both the literature review and experimental results demonstrate that mixing due to the water inlet plume is a highly influential factor and was therefore taken into account. Literature suggests that a plethora of factors impact mixing due to inlet flows, such as inlet velocity and inlet configuration

One other important factor is the temperature of the inlet water with regards to the local water temperature to which it is being injected. For instance, if the inlet water is injected close to the bottom of the tank and happens to be warmer than the local layers of stratified water, the upward direction of the buoyancy force acting upon it will drive the incoming water up.

The warmer the inlet water, the further up the tank it will go and as the water plume rises, the layers it passes are entrained into it, they are thus mixed and warmed, while the inlet jet is cooled. Eventually the plume reaches a level within the tank that matches its own temperature and stops climbing.

The model used empirical data from the experimental phase to determine the extent to which inlet water mixed with tank water. Mixing was simulated by fully homogenising temperature at the bottom of the tank. The volume to be mixed was based on inlet flow and tank temperature.

\section{Natural convection}

Measurements showed that in a stratified tank, the average temperature of all the layers up to and including any specific control volume will only ever be the same as or lower than the temperature of that given control volume.

The adopted solution scanned the tank from the bottom upwards and compared the temperature of every control volume with the accumulated average temperature of the layers below and including said control volume. If the mathematical routine detected that an accumulated average temperature below any point along the tank's height, was higher than that of said point's actual temperature, it concluded that there must be hotter layers further down and thus natural convection must take place. 


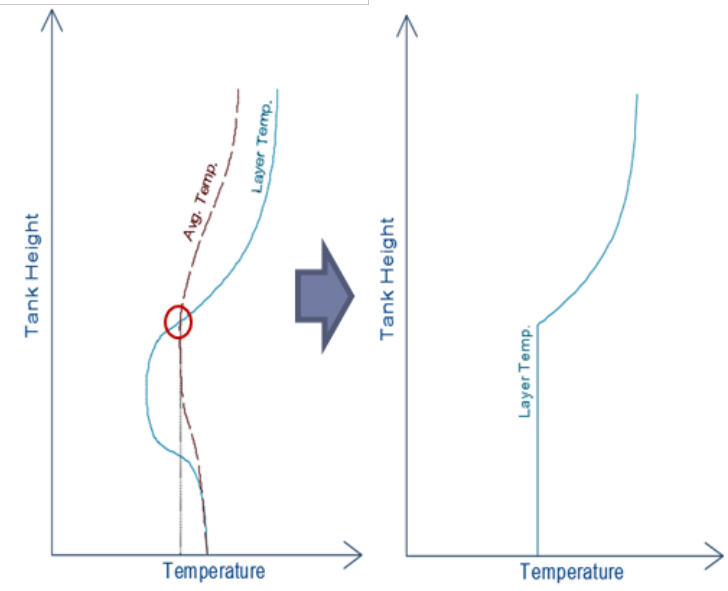

Fig. 9. Natural convection correction

To simulate convection, the first control volume that was warmer than the average accumulated temperature of the layers below and including it was found. Then the temperatures of all the control volumes below and including said layer were set to the average temperature (energy conservation) between the bottom and the stated layer to create a new temperature profile that no longer had warmer regions.

\subsubsection{Validation of the numerical model}

Figure 10 shows the $6 \times 4$ litres/minute simulation that reproduces the experimental data obtained from temperature measurements (Figure 4).

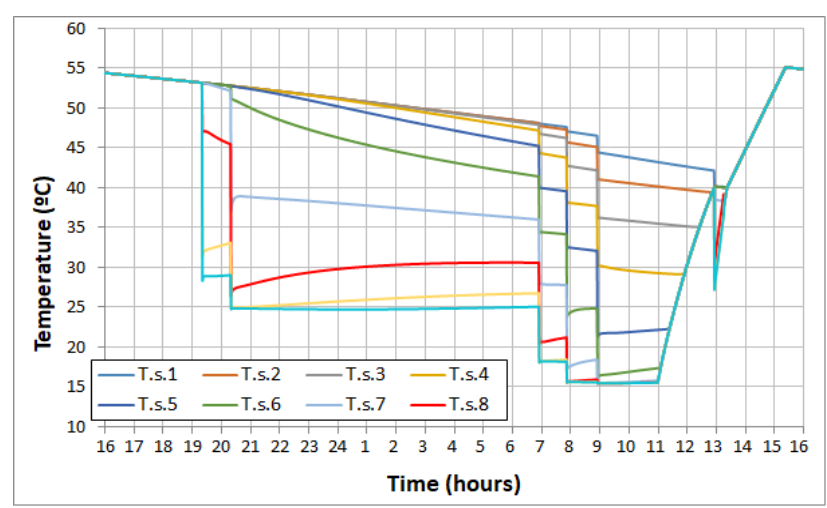

Fig. 10. Numerical results of a DHW consumption type

Figure 11 demonstrates that the model's ability to suitably mimic reality is not limited to inlet/outlet flow rates or the number of daily consumptions as in each case simulated results were indeed very similar to experimental results. Simulated results matched experimental results closely throughout the day, demonstrating that the model was capable of simulating a plethora of scenarios reliably and accurately with regards to the lower layers of the tank.

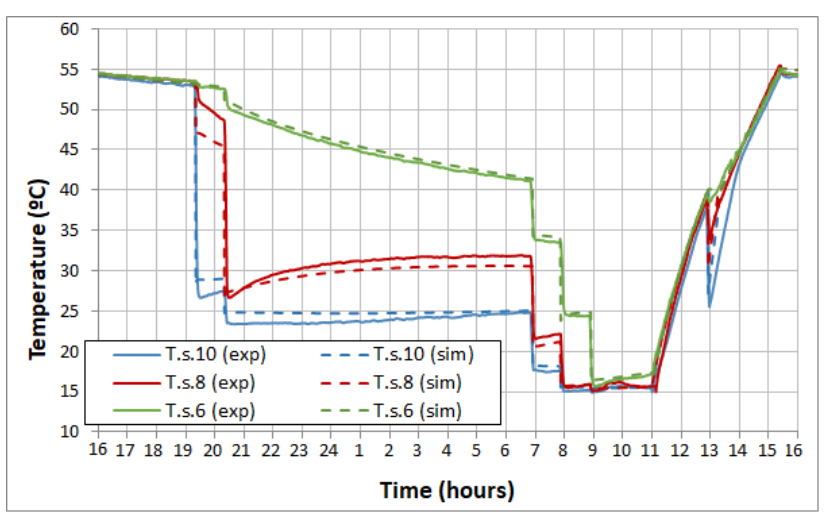

Fig. 11. Numerical vs Measurements of a DHW consumption

\section{Modelling application}

Once the whole simulation model was validated, it was used to simulate the curves from Standard EN 16147. There are 5 different test cycles (S, M, L, XL and XXL). Each of them defines energy consumption (in $\mathrm{kWh}$ equivalent of hot water tapped) along the 24 hours of a day. The norm defines the starting time of each tapping and the total energy content.

In the present work tapping cycle $\mathrm{L}$ has been simulated.

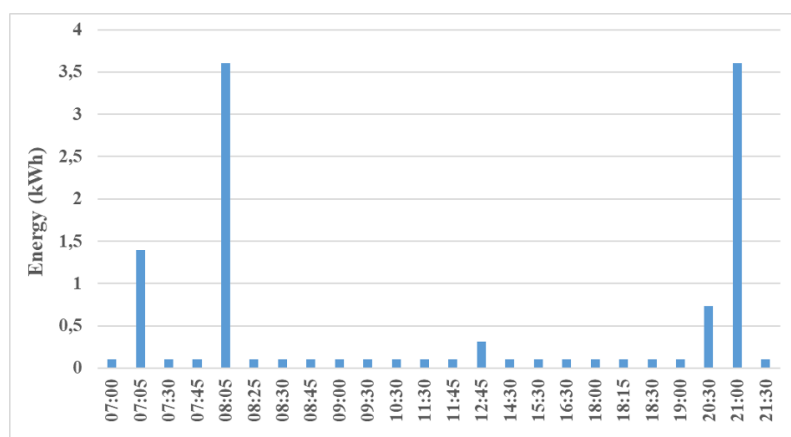

Fig. 12. Tapping profile. Curve L from EN 16147

The starting time and energy consumption for the L curve is shown in Figure 12. The L curve includes 24 DHW consumptions a day, representing the typical consumptions in a family dwelling: 19 small consumptions of $0.105 \mathrm{kWh}$, a shower of $1.4 \mathrm{kWh}$, two dish washing machine consumptions of $0.315 \mathrm{kWh}$ and $0.735 \mathrm{kWh}$, and two bathroom consumptions of 3.605 $\mathrm{kWh}$. This results in a total thermal energy consumption of $11.655 \mathrm{kWh} /$ day. It must be pointed out that the accumulator heat losses are not included in this amount. For dish washing tappings, a water temperature of $45 \mathrm{~K}$ above cold water temperature is required. However, the required temperature cannot always be achieved by the heat pump. In these cases, it is assumed that an electrical resistance heater is used to provide the additional temperature increase. Consequently, the electrical consumption of this resistance has been considered during the calculation of the final COP.

Simulation results are shown at Table 4 for an inlet air temperature to the evaporator of $20^{\circ} \mathrm{C}$ and an ambient temperature in the accumulator of $20^{\circ} \mathrm{C}$. An inlet water temperature of $10^{\circ} \mathrm{C}$ has been considered for all consumptions. 
Table 4. Simulated results. Curve L from EN 16147

\begin{tabular}{|l|c|c|c|}
\hline Useful energy from the HP & QHР,Tар & 11.558 & $\mathrm{kWh}$ \\
\hline Useful energy from resistance & QEL,Tap & 0.084 & $\mathrm{kWh}$ \\
\hline Total useful energy & QTар $_{\text {Ta }}$ & 11.642 & $\mathrm{kWh}$ \\
\hline Electrical energy input & W $_{\text {EL,HP,Tap }}$ & 4.264 & $\mathrm{kWh}$ \\
\hline Standby power input & P $_{\text {es }}$ & 0.031 & $\mathrm{~kW}$ \\
\hline Time of the test & tTTC & 28.250 & $\mathrm{~h}$ \\
\hline Total electrical energy consum. & WEL,TC $_{\text {E }}$ & 4.214 & $\mathrm{kWh}$ \\
\hline & COP & $\mathbf{2 . 7 6 3}$ & \\
\hline
\end{tabular}

According to the simulation, along one day, the heat pump provides $13.821 \mathrm{kWh}$ of thermal energy to heat the water, $2.166 \mathrm{kWh}$ of which are used to provide for the accumulator heat losses. This way, the useful thermal energy provided to fulfil DHW needs is $11.655 \mathrm{kWh}$. The total electrical consumption is $4.214 \mathrm{kWh}$.

The COP of the heat pump, calculated as the ration of supplied thermal energy and electrical energy consumption is 3.28 . However, according to the norm, only the DHW useful thermal energy must be used in the calculation, resulting in a COP of 2.76 .

Figure 13 shows the evolution of the temperature stratification within the DHW accumulator, along the simulation for the L curve consumption profile.

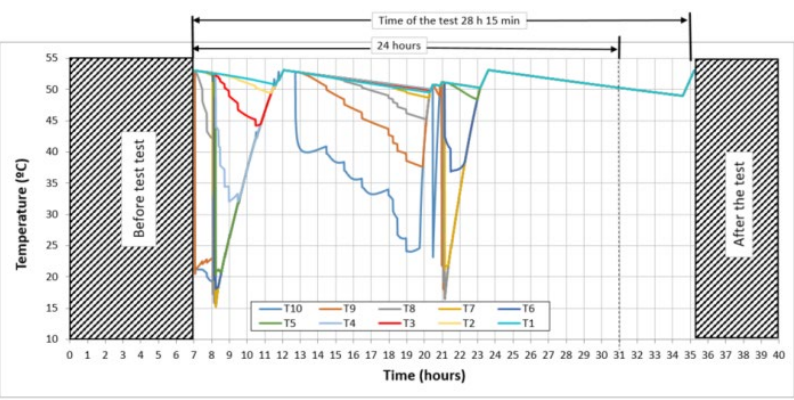

Fig. 13. Stratification results from the simulation. T1 corresponds to the temperature in the upper part of the tank and $\mathrm{T} 10$ in the lower part

\section{Conclusions}

An experimental work where a heat pump for domestic hot water production (DHW-HP) that is powered from photovoltaic panels (PV) and from the grid has been carried out.

The results from the experimental work have been used to elaborate a computer model capable of simulating the performance of the system under different scenarios (climate conditions, thermal demand, etc.).

Using MATLAB, the experiments were replicated numerically to substantial degree accuracy. The defined model was able to mimic tank behaviour under a number of different draw profiles and inlet flowrates, proving its versatility and reliability. In terms of practicality, time efficiency and ease of use the model also showed great promise, as it took less than one minute to simulate 24 hours-worth of data.
According to the simulation results, it can be concluded that the developed model has been properly validated, since it is capable of replicating the experimental results with a high accuracy level.

Finally, the computer model has been used to simulate the DHW tapping cycle S, M and L from the Standard EN 16147. Results from the simulation of the tapping cycle $\mathrm{L}$ have been included in the present article. They show that the COP of the tested heat pump is 2.76 , which is higher than the minimum required value of 2.5 , higher than 2.5 , so that it can be considered as renewable source of energy.

\section{References}

1. Directive 2010/31/EU on the energy performance of buildings - 19 May 2010

2. Directive (EU) $2018 / 844$ on the energy performance of buildings - 9 July 2018

3. G. Morrison, T. Anderson and M. Behnia, Seasonal performance rating of heat pump water heaters, Sol. Energy, Elsevier, 76, pp. 147-152, (2004)

4. J. Guo, J. Wu, R. Wang and S. Li, Experimental research and operation optimization of an air-source heat pump water heater, Appl. Energ., Elsevier, 88, pp. 4128-4138, (2011)

5. European Commission, Commission Decision of 1 March 2013 establishing the guidelines for Member States on calculating renewable energy from heat pumps from different heat pump technologies pursuant to Article 5 of Directive 2009/28/EC of the European Parliament and Council, Brussels: EU, (2013)

6. Zhiyi Wang, Jiachen Zhong, Gaoyuan Wang, Research on the improvement of defrosting bottom freezing to the heat pump unit with subcooler at low ambient temperature, Energy Procedia, 158, pp. 2092-2097, (2019)

7. Zhangyuan Wang, Peng Guo, Haijing Zhang, Wansheng Yang, Sheng Mei, Comprehensive review on the development of SAHP for domestic hot water, Renew. Sust. Energ. Rev., 72, pp. 871881 (2017)

8. M. Mohanraja, Ye. Belyayevb, S. Jayaraj, A. Kaltayev, Research and developments on solar assisted compression heat pump systems - A comprehensive review (Part A: Modeling and modifications), Renew. Sust. Energ. Rev., 83, pp. 90-123, (2018)

9. Sandeep S. Joshi, Ashwinkumar S. Dhoble, Photovoltaic -Thermal systems (PVT): Technology review and future trends, Renew. Sust. Energ. Rev., 92, pp. 848-882, (2018) 
10. N. Aste, C. Del Pero, F. Leonforte, Water PVTcollectors performance comparison, Energy Procedia, 105, pp. 961-966, (2017)

11. Yanping Du, Christopher J. Fell, Benjamin Duck, Dong Chen, Kurt Liffman, Yinan Zhang, Min Gu, Yonggang Zhu, Evaluation of photovoltaic panel temperature in realistic scenarios, Energ. Convers. Manage., 108, pp. 60-67, (2016)

12. Chow, T., F. Fong, K., Pei, G., Ji, J., He, M., Potential use of photovoltaic-integrated solar heat pump system in Hong Kong, Appl. Therm. Eng., 30, pp. 1066-1072, (2010)

13. Fang, G., Hu, H., Liu, X., Experimental investigation on the photovoltaic thermal solar heat pump air-conditioning system on water-heating mode. Exp. Therm. Fluid. Sci., 34, pp. 736-743, (2010)

14. Xingxing Zhang, Xudong Zhao, Jingchun Shen, Xi $\mathrm{Hu}$, Xuezhi Liu, Jihuan $\mathrm{Xu}$, Design, fabrication and experimental study of a solar photovoltaic/loopheat-pipe based heat pump system, Sol. Energy., 97,551-568, (2013)

15. Hong Li, Yue Sun, Operational performance study on a photovoltaic loop heat pipe/solar assisted heat pump water heating system, Energ. \& Build.,158, pp. 861-872, (2018)

16. F.J. Aguilar, S. Aledo and P.V. Quiles, Experimental study of the solar photovoltaic contribution for the domestic hot water production with heat pumps in dwellings, Appl. Therm. Eng., 101, pp.379-389, (2016)

17. EN 16147, Heat pumps with electrically driven compressors - Testing and requirements for marking for domestic hot water units (2010)

18. Technical specifications for installations connected to the network, IDAE, (2011) 